\title{
Career Concerns and Ambiguity Aversion
}

\author{
5 May 2008
}

Eric Rasmusen

\begin{abstract}
Why do people have ambiguity aversion, preferring, a gamble with a $50 \%$ chance of success to one whose expected probability of success is $50 \%$ but where that $50 \%$ is an unbiased estimate? The answer modelled here, in the spirit of the career concerns literature, is learning: a risk-averse person does not wish observers to learn whether he is good or bad at estimating probabilities. He therefore prefers a gamble with objective probabilities.
\end{abstract}

Dan R. and Catherine M. Dalton Professor, Department of Business Economics and Public Policy, Kelley School of Business, Indiana University. BU 438, 1309 E. 10th Street, Bloomington, Indiana, 47405-1701. Office: (812) 855-9219. Fax:812-855-3354. erasmuse@indiana.edu, http://www.rasmusen.org. This paper: http://www.rasmusen.org/papers/ambiguity-rasmusen.pdf.

Keywords and Codes: D81, G31, L21, ambiguity, Ellsberg paradox, career concerns I thank Nuffield College,Oxford University for its hospitality. 


\section{Introduction}

Under our standard theory of expected utility, only expected utility matters, not how its probabilities are computed. A person should be indifferent between a a gamble with a known, objective, probability of success to one with the same expected probability but greater dispersion. If he is prefers the known probability we say he exhibits "ambiguity aversion." One variant of ambiguity aversion is to prefer a gamble with a single probability of success (e.g., .7) to one with a compound probability (e.g., 50\% chance of .6, 50\% chance of .8). The Ellsberg Paradox is an example (Ellsberg, 1961). Most people prefer a gamble in which they win if a red ball is drawn from urn A with 100 balls, 50 of which are red and 50 blue; to the same gamble with urn B which has 100 balls of an unknown color mix. It cannot be that they guess that there are less than 50 red balls in the second urn, because they also prefer urn A if they win when a blue ball is drawn. A second variant is to dislike making decisions that rely on estimated probabilities. Businesses dislike venturing into situations in which probabilities are based on poor information, e.g., providing earthquake insurance when a large earthquake is a rare event.

Such preferences are the subject of a large literature, and have been axiomatized in two of its best known articles, Gilboa and Schmeidler (1989) and Schmeidler (1989). I wish here to use instead a structural approach in the spirit of the career concerns literature. In that literature, managers take actions not just to maximize current performance, but to protect their reputation for high ability. This can make them either more averse to risk or less than they otherwise would be.

In the present context, career concerns will not make the manager averse to risk, but to ambiguity. Managers dislike ambiguity because it can make them look stupid. If their utility is concave in reputation, they will avoid a choice which displays their ability. In most models of career concerns and project choice, what is to be learned is the manager's ability to influence the probability of success, e.g. Milbourn, Shockley and Thakor (2001). Here, it will be the manager's ability to estimate the probability of success. A manager's ability will become better known if observers learn something about

the manager's subjective probability of success and something about the objective probability of success. 


\section{The Model}

The unambiguous project, $\mathrm{A}$, is successful with probability $p_{a}$. The ambiguous project, $\mathrm{B}$, is successful with probability $p_{b}$, which is $\beta$ or $\alpha>\beta$ with equal probability. Profit is 0 if the chosen project is a failure, 1 if a success.

The manager gets a private signal Alpha or Beta of Project B's success probability. With probability .5 he is untalented and his signal is correct with probability $\theta=\underline{\theta}$ (e.g. his signal is Alpha and the project's success rate is $\alpha$ ). With probability .5 he is talented and his signal is correct with probability $\theta=\bar{\theta}$, where $.5 \leq \underline{\theta}<\bar{\theta} \leq 1$.

The manager's payoff function is

$$
u(\text { profit })+v(T)
$$

where $u^{\prime}, v^{\prime}>0$ and $u^{\prime \prime}, v^{\prime \prime}<0$.

The manager might care about $T$ simply from pride, but he might also care because his future compensation will depend on whether the market thinks he is good at estimating probabilities. In this model, a talented manager will have higher expected profit than an untalented one, and so would be paid more if his talent were known.

Neither market nor manager knows if he is talented. Denote the market's estimate of the probability that he is talented by $T$. Denote the manager's estimate of $p_{b}$ by $\widehat{p}_{b}$.

The manager's expected payoffs from Project A and B are thus

$$
\left[p_{a} u(1)+\left(1-p_{a}\right) u(0)\right]+v(.5)
$$

and

$$
\left[\widehat{p}_{b} u(1)+\left(1-\widehat{p}_{b}\right) u(0)\right]+\left[\widehat{p}_{b} v(T \mid \text { Success })+\left(1-\widehat{p}_{b}\right) v(T \mid \text { Failure })\right]
$$

These assumptions imply that the manager is risk averse and would prefer a safe project with a profit of $p$ to a gamble. Nonetheless, the ambiguity of project B's probability of success does not matter in the profit part of the 
manager's utility function. If $p_{a}$ and $\widehat{p}_{b}$ both equal some number $p$, then the expected payoffs are

$$
[p u(1)+(1-p) u(0)]+v(.5)
$$

and

$$
[p u(1)+(1-p) u(0)]+[p v(T \mid \text { Success })+(1-p) v(T \mid \text { Failure })]
$$

\section{Reputation}

When the manager receives the signal Alpha or Beta he does not thereby learn anything about his ability. Both qualities of project $\mathrm{B}$ have equal probability, so he is equally likely to receive each signal.

The manager's expected probability of success for Project B if his private signal is Beta is

$$
\widehat{p}_{b}=\operatorname{Pr}(\text { Success } \mid \text { Beta })=.5(\underline{\theta} \beta+(1-\underline{\theta}) \alpha)+.5(\bar{\theta} \beta+(1-\bar{\theta}) \alpha)
$$

because with probability .5 he is untalented, in which case the Beta signal is correct with probability $\underline{\theta}$ so $p_{b}=\beta$, and incorrect with probability $1-\underline{\theta}$ so $p_{b}=\alpha$. With probability .5 he is talented, in which case the Beta signal is correct with probability $\bar{\theta}$ so $p_{b}=\beta$, and incorrect with probability $1-\bar{\theta}$ so $p_{b}=\alpha$.

As a running example, let $\beta=.3, \alpha=.7, \underline{\theta}=.6, \bar{\theta}=.9$. Then

$$
\widehat{p}_{b}=.5((.6)(.3)+(.4)(.7))+.5((.9)(.3)+(.1)(.7))=.40 \text {. }
$$

Similarly, if his private signal is Alpha,

$$
\begin{aligned}
\widehat{p}_{b}=\operatorname{Pr}(\text { Success } \mid \text { Alpha }) & =.5((1-\underline{\theta}) \beta+\underline{\theta} \alpha)+.5((1-\bar{\theta}) \beta+\bar{\theta} \alpha) \\
& =.5((.4)(.3)+(.6)(.7))+.5((.1)(.3)+(.9)(.7))=.60 .
\end{aligned}
$$

If $p_{a}<E\left(p_{b} \mid\right.$ Beta $)$, the manager would adopt project $\mathrm{B}$ regardless of his signal. The market could not learn anything about his talent, regardless 
of whether it observed the success or failure of the project, or even the true probability $p_{b}$.

If Project B is chosen and $E\left(p_{b} \mid\right.$ Beta $)<p_{a}<E\left(p_{b} \mid A l p h a\right)$, the market can deduce that the signal was Alpha. This has no immediate use in learning the manager's talent, but in conjunction with observing Success or Failure it will be useful.

After observing Success or Failure, the market forms its posterior belief about the manager's talent. If the project is successful and the signal was Alpha, then using Bayes's Rule, the belief is

$$
\begin{aligned}
T(\text { Success })=\operatorname{Pr}(\text { Talented } \mid \text { Success, Alpha }) & =\frac{\operatorname{Pr}(\text { Success } \mid \text { Talented,Alpha }) \operatorname{Pr}(\text { Talented })}{\operatorname{Pr}(\text { Success } \mid \text { Alpha })} \\
& =\frac{(.5(1-\bar{\theta}) \beta+.5 \bar{\theta} \alpha)(.5)}{(.5(1-\bar{\theta}) \beta+.5 \bar{\theta} \alpha)(.5)+(.5(1-\underline{\theta}) \beta+.5 \underline{\theta} \alpha)(.5)} \\
& =\frac{[(.5)(.1)(.3)+(.5)(.9)(.7)](.5)}{[(.5)(.1)(.3)+(.5)(.9)(.7)](.5)+(.5)(.4)(.3)+(.5)(.6)(.7)](.5)}=.550
\end{aligned}
$$

or

$$
\begin{aligned}
T(\text { Failure })=\operatorname{Pr}(\text { Talented } \mid \text { Failure }, \text { Alpha }) & =\frac{\operatorname{Pr}(\text { Failure } \mid \text { Talented,Alpha }) \operatorname{Pr}(\text { Talented })}{\operatorname{Pr}(\text { Failure } \mid \text { Alpha })} \\
& =\frac{(.5 \bar{\theta}(1-\alpha)+.5(1-\bar{\theta})(1-\beta))(.5)}{(.5 \bar{\theta}(1-\alpha)+.5(1-\bar{\theta})(1-\beta))(.5)+(.5 \underline{\theta}(1-\alpha)+.5(1-\underline{\theta})(1-\beta))(.5)} \\
& =\frac{[.5(.9)(.3)+.5(.1)(.7)](.5)}{[.5(.9)(.3)+.5(.1)(.7)](.5)+[.5(.6)(.3)+.5(.4)(.7)](.5)}=.425 .
\end{aligned}
$$

The expected value of $T$ is

$$
\begin{aligned}
E T & =\operatorname{Pr}(\text { Success } \mid \text { Alpha }) \operatorname{Pr}(\text { Talented } \mid \text { Success, Alpha }) \\
& +\operatorname{Pr}(\text { Failure } \mid \text { Alpha }) \operatorname{Pr}(\text { Talented } \mid \text { Failure }, \text { Alpha }) \\
& =\bar{\theta}(.5)+(1-\bar{\theta})(.5)=.5
\end{aligned}
$$

where the second line is obtained by substituting from (9) and (10)

If the manager's were risk-neutral in reputation, his decision to accept the project would be unaffected by the market learning about his ability, but we have assumed he is risk averse. By Jensen's Inequality, $E(v(T))<$ 
$v(E(T))$ because $v$ is concave and $T$ is stochastic. Thus, if $\widehat{p}_{b}=p_{a}$, the manager would choose Project A, exhibiting ambiguity aversion.

Thus, we can explain ambiguity aversion as the result of career concerns without any need to resort to irrationality or direct disutility. There are two reasons why the firm's owners should design compensation to encourage the manager to take on ambiguous projects: (1) to get him to choose the most profitable project, since otherwise he might prefer Project A even if $p_{a}<\widehat{p}_{b}$; and (2) to learn his ability to decide whether to keep him or hire a new manager. This second advantage would make the owners actually ambiguity loving.

\section{Fifty-Fifty Hindsight}

"Hindsight bias" is the tendency of people to fool themselves into believing ex post that they would have made a different decision ex ante. If we increase the ex post information available to the market, the market will punish or reward the manager in a way that looks like hindsight bias but is actually unbiased.

In the last section's model, when the market observes Success it deduces that the manager, having observed Alpha, was more likely than not talented and the true probability was $\alpha$. Now assume that once the project is completed the market learns whether $p_{b}=\alpha$ directly- regardless of actual success, he ex ante probability of success becomes common knowledge. This is even better information for learning about the manager's ability.

If the market observes $p_{b}$ directly, it does not need to use the imperfect signal of Success or Failure. Rather, $T$ becomes

$$
\begin{aligned}
& T\left(p_{b}=\alpha\right)=\operatorname{Pr}\left(\text { Talented } \mid \text { Alpha }, p_{b}=\alpha\right)=\frac{\operatorname{Pr}\left(p_{b}=\alpha \mid \text { Talented,Alpha }\right) \operatorname{Pr}(\text { talented })}{\operatorname{Pr}\left(p_{b}=\alpha \mid \text { Alpha }\right)} \\
& =\frac{\bar{\theta}(.5)}{\bar{\theta}(.5)+\underline{\theta}(.5)}=.6 .
\end{aligned}
$$




$$
\begin{aligned}
& T\left(p_{b}=\beta\right)=\operatorname{Pr}\left(\text { Talented } \mid \text { Alpha, } p_{b}=\beta\right)=\frac{\operatorname{Pr}\left(p_{b}=\beta \mid \text { talented,Alpha }\right) \operatorname{Pr}(\text { talented })}{\operatorname{Pr}\left(p_{b}=\beta \mid \text { Alpha }\right)} \\
& =\frac{(1-\bar{\theta})(.5)}{(1-\bar{\theta})(.5)+(1-\underline{\theta})(.5)} \\
& =\frac{(.1)(.5)}{(.1)(.5)+(.4)(.5)}=\frac{.05}{.05+.20}=.2 .
\end{aligned}
$$

The gap between $T\left(p_{b}=\beta\right)$ and $T\left(p_{b}=\alpha\right)$ is bigger than the gap between $T$ (Failure) and $T$ (Success) because

$$
T\left(p_{b}=\alpha\right)=\frac{\bar{\theta}(.5)}{\bar{\theta}(.5)+\underline{\theta}(.5)}=\frac{\bar{\theta} \alpha}{\bar{\theta} \alpha+\underline{\theta} \alpha}>\frac{\bar{\theta} \alpha+W_{1}}{\bar{\theta} \alpha+W_{1}+\underline{\theta} \alpha+W_{2}}
$$

if $W_{1}<W_{2}$. From euation (9), however, $T$ (Success) equals that right-hand expression in $(14)$, however, if we set $W_{1}=(1-\bar{\theta}) \beta$ and $W_{2}=(1-\underline{\theta}) \beta$, so $T\left(p_{b}=\alpha\right)>T($ Success $)$ not just for our numerical example but in general. It can be similarly be shown that $T\left(p_{b}=\beta\right)<T($ Failure $)$.

Thus, if the market has 50-50 hindsight and observes $p_{b}$ directly instead of just observing Success or Failure, the manager's risk from the ambiguous project rises. He has reason to prefer a project whose success probability is objectively known to the public rather than a project whose success probability he has estimated, even if the probabilities turn out the same. Further-

more, the manager is not just reacting to a behavioral bias on the part of the market: if what would have been the best decision ex ante becomes clear ex post, the market can use the information to better learn the manager's ability.

\section{References}

Ellsberg, D., 1961, Risk, Ambiguity, and the Savage axioms, Quarterly Journal of Economics 75, 643-669.

Gilboa, I. and D. Schmeidler, 1989, Maxmin expected utility with nonunique prior, Journal of Mathematical Economics, 18, 141-153. 
Milbourn, T., R. Shockley and A. Thakor, 2001, Managerial career concerns and investments in information, RAND Journal of Economics 32, 334351.

Schmeidler, D., Subjective probability and expected utility without additivity, Econometrica 57, 571-587. 